\title{
Meetings and Conferences
}

\section{Oncology \\ Research and \\ Treatment}

Oncol Res Treat 2019;42:430

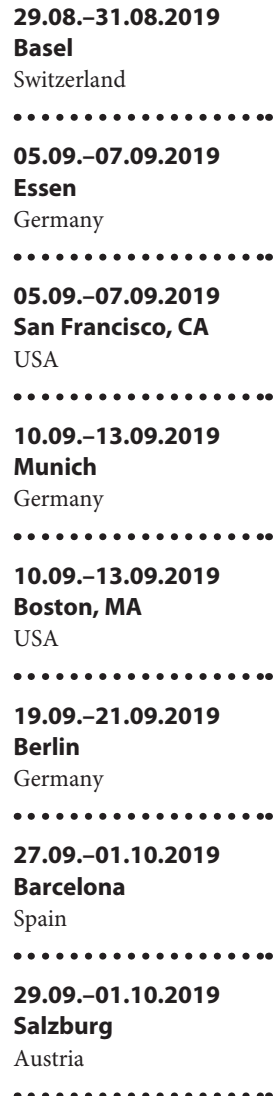

11.10.-14.10.2019

Berlin

Germany

22.10.-25.10.2019

Barcelona

Spain

................

08.11.-09.11.2019

London

UK

................

29.11.-30.11.2019

Kiel

Germany

................

19.02.-22.02.2020

Berlin

Germany

19.02.-22.02.2020

Berlin

Germany

•...............

18.03.-20.03.2020

Barcelona

Spain
Advanced Prostate Cancer Consensus Conference (APCCC 2019)

Master of Disaster: Komplikationsmanagement in der Senologie und Gynäkologischen Onkologie

5th World Congress on Controversies in Breast Cancer (CoBrCa)

Joint Meeting of the German Society for Immunology (DGfI) and the Italian Society of Immunology, Clinical Immunology and Allergology (SIICA)

CAR-TCR Summit

9. Kongress Forum Operative Gynäkologie

ESMO 2019 Congress

Gemeinsame Jahrestagung der Deutschen, Österreichischen und Schweizerischen Gesellschaft für Thoraxchirurgie

Jahrestagung der Deutschen, Österreichischen und Schweizerischen Gesellschaften für Hämatologie und Medizinische Onkologie

27th Annual Congress of the European Society of Gene and Cell Therapy (ESGCT)

MAP 2019 - Molecular Analysis for Personalised Therapy

22. Ostsee-Seminar

34. Deutscher Krebskongress

8th European Conference on Tobacco or Health - ECToH 2020

12th European Breast Cancer Conference (EBCC 12)
Information:

www.apccc.org/apccc2019.html

\section{Information:}

www.masterofdisaster.org

Information:

cobrca.org

Information:

www.immunology-conference.de

Information:

car-tcr-summit.com

Information:

www.if-kongress.de/veranstaltungen

\section{Information:}

www.esmo.org/Conferences/ESMO-2019-Congress

\section{Information:}

thoraxchirurgie2019.at/

\section{Information:}

www.dgho.de/veranstaltungen/jahrestagung/zukuenftigejahrestagungen

\section{Information:}

www.esgct.eu/Congress/Barcelona-2019.aspx

\section{Information:}

www.esmo.org/Conferences/MAP-2019-Molecular-

Analysis-for-Personalised-Therapy

\section{Information:}

www.if-kongress.de/veranstaltungen

\section{Information:}

www.dkk2018.de

\section{Information:}

www.ng-akademie.de/details/ECToH2020.html

Information:

www.ecco-org.eu/EBCC 